\title{
Gender conversations in Zimbabwe: A precursor of male gaze in visual art practices
}

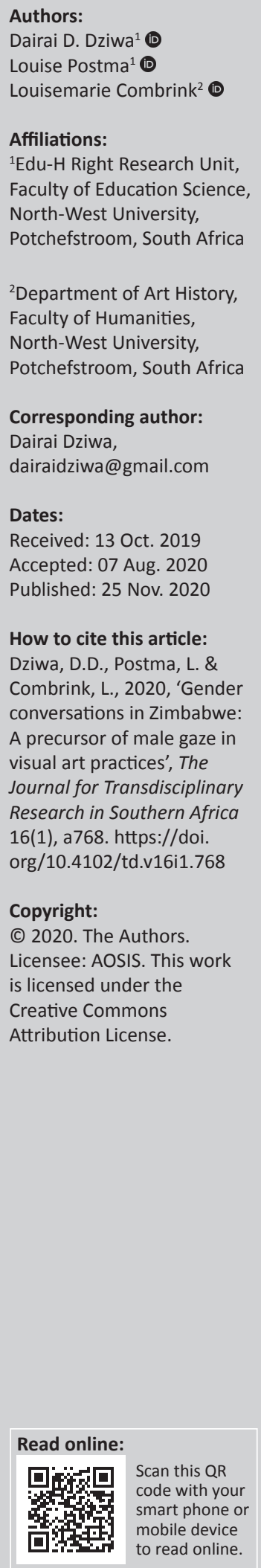

Authors:

Louise Postma ${ }^{1}$

Affiliations:

${ }^{1}$ Edu-H Right Research Unit,

Faculty of Education Science, North-West University,

${ }^{2}$ Department of Art History,

Faculty of Humanities,

North-West University,

Potchefstroom, South Africa

Corresponding author:

Dairai Dziwa,

dziwa@gmail.com

2019

How to cite this article: Combrink, L, conversations in Zimbabwe: Journal for Transdisciplinary Research in Southern Africa

Copyright:

(c) 2020. The Authors. Licensee: AOSIS. This work

mobile device to read online.
Masculine hegemonic predisposition dominates the gender culture in Zimbabwe. From this perspective, the notion of the male gaze entails that visual interpretation, amongst other things, at encoding and decoding levels is consequently performed with a specific hegemonic 'lens'. It follows that much of visual art, films and advertisements are created to please and reinforce a male-biased perspective which renders women powerless and subordinate. In the visual arts, this is particularly evident in the manner that the representation of space reflect this bias. Guided by critical phenomenology, this study adopted an interpretive methodology informed by decolonial views to explore and challenge gender identity constructions in visual culture. Engagement with gender literature and visual discourse analysis revealed the demeaning effects of patriarchy and also coloniality on women in much of Zimbabwean art. The discourse of decolonial activist art opposes the male gaze and aims to disrupt the power dynamics which position women to be inferior or less visible in the public art space. This type of activist art is concerned with the possible critical transformative impact of the visual arts in contesting and resisting gender dichotomy, imbalances and inequality.

Keywords: male gaze; masculinity; hegemony; heteronormativity; gender construction; decoloniality; activist art.

\section{Introduction}

The dominance of the male gaze or the androcentric view in art is an embodiment of a patriarchal ideology. The ideology of male privilege and domination is predicated on biased perceptions that artists and viewers bring to the interpretation of visual artworks. Studies attest that Zimbabwean gender constructions ascribe to patriarchy (Chabaya, Rembe \& Wadesango 2009; Gordon 1994; Gudhlanga, Chirimuuta \& Bhukuvhani 2012; Kamabarami 2006; Parpart 1995). This article first peruses the prevalence of masculine hegemony, concomitant with discrimination and injustices perpetuated against women. Secondly, visual discourse analysis of selected artworks demonstrates the rise of (de)colonial visual culture in Zimbabwe, whether it is or it is not entrapped in a hegemonic male gaze. According to Mulvey (1999), the notion of the male gaze suggests that male dominance and supremacy inherent in visual culture are reflections of the patriarchal ideologies held in that society (Mulvey 1999). Some reviews of visual culture in Zimbabwe by Mugambi (2008), Samwanda (2013) and Winter-Irving (1994) concur with her views and reveal evidence of heteronormative power relations.

This article demonstrates that patriarchal gender ideology influences the male gaze in visual art practices. However, the dichotomous and asymmetrical patriarchal gender constructions are challenged and contested in discourse and some artistic productions. The aims of this article are to create awareness of unequal gender constructions and representations to explore the inherent paradox of power discourse and multiple masculinities in visual culture and to critically engage with visuality in a decolonial context aimed at gender equality. Artworks inevitably reflect the sentiments, desires and experiences of the culture in which they are produced and can, therefore, be agents of critical conscientisation and change (Barnet 2010).

\section{Conceptual and theoretical framework}

The conceptual and theoretical framework for this study is informed by cultural hegemonic theory (Gramsci 1994; Connell \& Messerschmidt 2005) and the male gaze (Mulvey 1999) in visual interpretation. Gender role stereotyping can be defined as the cultural association of men with strength, aggression and dominance and women with passivity, nurturing and subordination (Bourdieu 2001; Diamond 2002). Related to this is the concept of heteronormativity, which Butler 
(1991) problematises as the belief that people can be divided into distinct and complementary genders (masculinity and femininity) with 'natural' and biological determinist gender roles. Heteronormativity, in this sense, is a form of gender stereotyping indexed by biological sex. Gender constructions in the context of this article refer to dichotomous masculine and feminine roles and norms that concern hegemonic (superior) and challenging (concomitant subordinately represented) views.

Patriarchy and related cultural-hegemonic practices inform the asymmetrical power imbalances between men and women as embodiments of patriarchal gender culture (Mutekwe \& Mobida 2014). 'Cultural hegemony' describes the domination of societal practices by the dominant players in a culture who shape the pervasive beliefs, explanations, perceptions and values of that society (Connell \& Messerschmidt 2005). The initial theoretical application of cultural domination was in the form of a Marxist analysis of economic class (Gramsci comes to mind in this regard) (Gramsci 1994). Cultural hegemony, in the context of the present article, describes a dominant social group, namely men, as the controller of the economy and other societal structures and refers to forms of supremacy obtained by some social, political, economic and religious groups (males) primarily by consent (thus naturalising hegemony) rather than coercion, and by moral and intellectual leadership rather than by domination. Every social structure has its own common sense and its own good sense, and these are agreed upon in society (Gramsci 1994). Given such cultural hegemony, the girls and boys are predisposed to particular asymmetrical positions of power divisions that become entrenched as 'knowledge' and beliefs that have a bearing on perceptions and/or the interpretation of culture and its artefacts. Masculinity, as a construct, is historically situated in conquest, domination and exploitation of foreign territories by higher powers, and is thus profoundly related to colonial practices of domination, as the colonial project and its aftermath highlight the presumed political, economic and cultural superiority of the colonisers over the colonised.

There are multiple masculinities and power relations at play in a given society (Connell \& Messerschmidt 2005). Power is not solely conceptualised in terms of sexual differences because class difference, race and cultural capital and gender identity are also forms of masculine power (Freud 1995). Connell and Messerchmidt (2005) maintain that 'the hierarchy of masculinities is a pattern of hegemony, not a pattern of simple domination based on force'. There are, consequently, multiple hierarchies that can be discerned in societal structures such as schools, work places and communities, and therefore hegemony implies dominance in terms of culture, various social contexts as well as institutions and persuasions.

The notion of 'male gaze' was coined by Laura Mulvey in 1975 in an essay on cinematography entitled Visual Pleasure and Narrative Cinema. In her discussion on the role of women in films, she argued that women are often portrayed as objects and subordinates mainly because their representation in films favours a masculine vantage point. Women's role in visuality tends to reflect an inferior position to men, according to Mulvey, thus favouring male spectatorship (Mulvey 1999). Consequently, from a masculine perspective, women tend to be regarded as the bearer[s] of meaning and not the maker[s] of meaning. Mulvey (1999) argued that this inequality enforced the notion that 'men do the looking and women are to be looked at'. The male gaze also refers to social, economic and political advantages or rights in visual practices availed to men because of their hegemonic status, heteronormativity and gender identity, which this article argues have similar effects on perceptions of males and females in the context of producing and viewing artworks (Mulvey 1999).

Arguably, many artistic outputs and also interpretative practices reinforce entrenched gender identities predicated on male dominance emanating from cultural practices informed by masculinity (Dziwa 2016; Goffman 1987; Gramsci 1994). In this vein, Goffman (1987) has demonstrated a clear dichotomy in the portrayal of men and women in advertisements where their representations confirm culturally constructed and essentialist gender roles. Barnet (2010) concurs that artworks carry culturally embedded ideological meanings in their creation and consumption. According to Goffman (1987), much visual art practice ascribes to a heteronormative narrative that suggests a ritualised subordination where feminine representations are deliberately postured as subordinate to what is defined as masculine. Connell and Messerchmidt (2005) criticise this perception of hegemonic masculinities on the premise of problematic reification, as many practices tend to render unequal power relations as fixed. Masculinity can, however, neither be judged on the basis of women's subordination nor on men's dominance only. The exercising of power and the experience of subordination are not fixed. Activist art that addresses such practices heightens conscientisation and hopes to contribute towards liberation from oppression in this context.

\section{Gender conversations in Zimbabwe}

Whilst there are several studies and publications on gender constructs in Zimbabwe, we engage with authors who discuss gender ideologies that characterise the general Zimbabwean population. The studies referred to, in this article, peruse gender conversations taking place over 18 years (1994-2012) focusing on different population samples and nuances of gender identity.

Gordon (1994) reveals a patriarchal system in the gender asymmetry and dichotomy enacted in education policy, enrolments and school curriculum implementation: the selection and allocation of subjects at the school level were sexually indexed (e.g. girls were taught cooking and typing, they had lower enrolments at all grade levels and were under-enrolled in technical and vocational institutions) Gudhlanga et al. (2012). Secondary schools' enrolment ratio 
for girls (at $42 \%$ ) was also significantly lower than that of boys (58\%) (Mutekwe \& Mobida 2014).

Parpart (1995) investigated the impact of economic changes in Zimbabwe on women's employment and education and the degree to which patriarchal structures have restricted women's opportunities in economic and political spheres. The Women and Law in Southern Africa (WLSA) report indicates that patriarchal practices dominated inheritance disputes and prohibited women from achieving economic and political independence. Kamabarami (2006) revealed how female subordination is entrenched through home socialisation which shapes and perpetuates patriarchal imbalances and denies women control over their sexuality and income. Interviews with widowed women who visited the Central Hospital Social Work Department in Harare revealed their dependence on males for food, finances and shelter. These women's only hope was the provision by the social work department because they could not imagine themselves as being employable or as breadwinners. Zimstat (2016) indicates that men are dominant in most employment sectors: mining (89.2\%), construction (96.5\%), public administration and defense (73.6\%), manufacturing $(77.5 \%)$, finance and insurance $(65 \%)$ as well as transport and storage (91.2\%).

Chabaya et al. (2009) studied the persistence of gender inequality and perceptions as factors that impede the advancement of women to leadership positions in primary schools. Patriarchal ideologies relegating women to positions of submissiveness, docility and passiveness led to the persistent under-representation of women, especially in primary school leadership and administration. The influence of gender role stereotypes manifests in low self-esteem, lack of confidence and engraved subordination. The same authors Chabaya et al. (2009) evaluated the response of the school curriculum to the call for gender equality and sensitivity and found that the curriculum disadvantaged women through patriarchal customary law and, also, the colonial legacy. Textbooks also leaned towards gender insensitivity, the dominance of male content and a limited inclusion of heroines. Chabaya and Gudhlanga (2007) indicated that textbooks in history and literature have more heroes than heroines, thus pervading the perception supported by Dudu et al. (2008) that women have lower social significance as they are excluded from discourses on the heroic acts. Chabaya and Gudhlanga (2007) reiterate that most textbooks hold that men are the only inventors in the world. However, they noted some shifts towards the inclusion of gender equality aiming at subverting patriarchal ideologies. Connell and Messerchmidt (2005) hold that patterns of gender relations are, indeed, flawed when assuming that the dominance of men and the subordination by women are natural. These ideas may give rise to change and can contribute towards the liberation of women.

\section{Research methodology and design}

The present study is guided by critical phenomenology and adopts an interpretive paradigm as we sought to find meaning and gain understanding of visual art practices in
Zimbabwe. De Vos et al. (2011) and Creswell (2013) indicate that a phenomenological study describes the meaning of lived experiences by the participants.

Selected visual artworks were analysed using a critical visual discourse interpretation model (CVDIM) (Dziwa 2016) to deconstruct the visual content and to explore the prevalence of the male gaze as embedded in these works. Visual images are key to this study to explore the meanings that participants demonstrate of lived and perceived gender experiences in visual iconography. The CVDIM is a way to facilitate the interpretation of visual content and nuances of power relations (Dziwa 2016). It is a synthesis of interpretative frameworks gleaned from social semiotics (Kress 2010), deconstructionism (Derrida 1982) and intertextuality (Kristeva 1980). The artworks that have been perused are informed by culture and context, bearing testimony to how power relationships are portrayed by the artists. The viewer, also, comes to an image with her or his own engraved cultural perceptions and knowledge. To explore these issues, we used framing as the initial stage of the interpretation process to identify and describe the social scene represented in the visual images prior to analysing them. Framing an analysis focuses on the extrapolation of multiple interpretations of evidence in the frame(s). The intertextual approach (Kristeva 1980) was also an important visual analysis strategy to interpret and relate contextual issues to other visual experiences. Intertextuality helped to construct discursive meanings within the historical and cultural context of gender and patriarchy. Inferences were made from various forms of knowledge available to the viewers who were not bound to visual experiences only but also to entrenched cultural experiences and perceptions of masculinity. Derrida (1982) holds that visuals contain an infinite amount of information which is not static over time and cultural situatedness. The CVDIM has both dynamic and transformative characteristics that suit this methodological approach to explore the meanings and reception of visual images.

Ethical issues pertaining to gatekeeper's permission and ethical clearance were given less consideration because visual artworks as the main source of information are available in the public domain, galleries and public sites.

\section{Male gaze in Zimbabwe visual art practices}

The portrayal of men as dominant in visual images, suggesting a privileged male gaze, is pervasive in Zimbabwe's visual culture. For example, only males were selected to represent Zimbabwe at the Venice Biennale Art Exhibition (2015), namely Chiko Chazunguza, Masimba Hwati and Gareth Nyandoro (Kaboy 2015).

Masimba Hwati explores the transformation and evolution of knowledge systems that are indigenous to his background whilst experimenting with the symbolism and perceptions attached to cultural objects, expressed as an art movement 
known as 'The Energy of Objects'. Some of his artworks are masculine in content (see Figures 1 and 2), whilst all his portraits represent men who are wearing dark glasses with popular brand logos such as Facebook (a social media platform), Kentucky Fried Chicken (KFC) (a fast food franchise), Amstel (a beer) and Coca-Cola (a soft drink).

Sunglasses create a barrier between the eyes and the dangerous ultraviolet rays. Thus, sunglasses protect the eyes, prevent cataracts, muscular degeneration and cancer. Our critical interpretation of these artworks is guided by the question: why did Hwati portray only men in glasses? Also, why would Hwati affix these logos on the spectacles of male figures (Figure 1)? These leading brands have a global economic impact and therefore need no introduction. One may argue that the branded sunglasses are suggested as blinding devices, removing one's ability to see beyond hegemonic popular brands as desirable. What, then, is the significance of these products to viewers? Which practices of looking are hinted at? The presence of the male face and

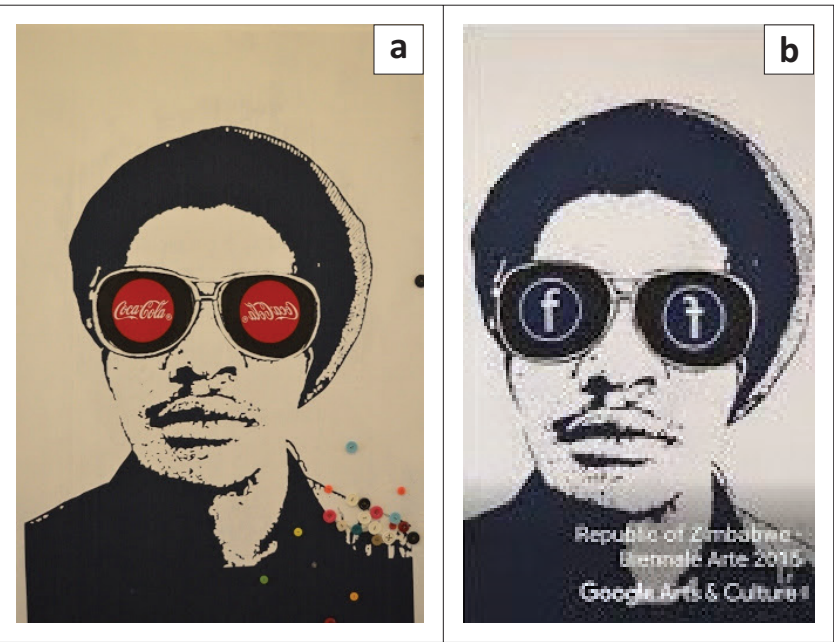

Source: (a) Artsandculture.google.com, n.d., Masimba Hwati. Urban Totems 6.., viewed n.d., from https://artsandculture.google.com/asset/masimba-hwati-urban-totems-6/FQGzm2Frkaqiw; (b) Artsandculture.google.com, n.d., Masimba Hwati. Urban Totems 2.., viewed n.d., from https://artsandculture.google.com/asset/masimba-hwati-urban-totems-2/LgGOfpgYOV16gw FIGURE 1: Curator's Black 2015, Masimba Hwati: (a) Coca Cola; (b) Facebook.

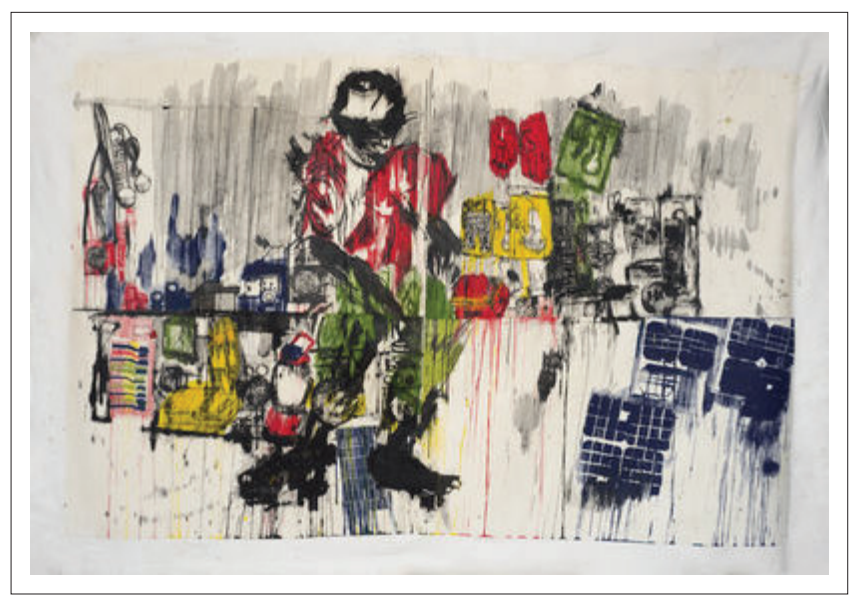

Source: Tiwani.co.uk, 2019, Gareth Nyandoro, Pajoji Electricals, viewed n.d., from https:// za.pinterest.com/pin/480970435207889175/

FIGURE 2: Pajoji electricals 2019 by Gareth Nyandoro. the straight assertive gaze suggest assertive dominance of the masculine. In conjunction with the branded sunglasses, these images undoubtedly show the influence of the male gaze as men are presumed to be the bearers of standard in a hegemonic popular cultural context reflected by the brands. The artworks, therefore, carry the message of discriminatory social classes (Messerschmidt 2019).

Pajoji Electricals (Figure 2) by Gareth Nyandoro, a graduate male artist from Chinhoyi University of Technology represents an open market selling electrical wares, solar panels, lights and accessories.

Very few women are involved in the business opportunities in these fields. As Gordon (1994) notes with reference to career choices in technical colleges, the electrical field is, therefore, dominated by males. Nyandoro suggests that this is a stereotype that associates men only with the industry of electrical wares. The title Pajoji electricals is a trade name translated as 'At George's electrical'. George is masculine, denoting the business as a male enterprise. In turn, restaurants or open-air kitchens which provide braai facilities and takeaway meals are often branded by feminine trade names such as 'Kwa Mai Daisy' or 'Kwa Mai Anna' (At Daisy's mother or At Anna's mother restaurant). The artwork can provoke a critical recognition that women are excluded from spheres associated with men and are instead associated with foodrelated industries that point to segregation based on stereotyped gender roles.

As previously noted, art often carries and expresses ideologies held by the culture in which it is produced (Barnet 2010). Women artists in Zimbabwe, interestingly, are also seen to portray themes with stereotyped gender roles, often portraying women in stereotypical domestic roles (Figure 3).

The image of Weya women shows many instances where women are in a domestic context, sweeping, carrying firewood and pounding grain, thereby reinforcing role stereotypes in visual representation (Dziwa 2016). Although women dominate the image, there are no heroines, but humble and sentimental domestic subjects. It is also notable that many sculptures by males as well as females that represent women show them doing domestic chores, carrying babies, giving birth and thus serving as images of entrenched gender roles (Mugambi 2008).

The sculpture titled First Lady Stone (Figure 4) by Agness Nyanhongo depicts the narrative of gender stereotyping by showing a female in the frame in her role of rearing and caring for children. In addition to the stereotyped act of child carrying, the face of the woman in the sculpture is tilted away from the viewers as a sign of subordination. According to Goffman (1987), this 'licensed withdrawal' is artistically created to show submission and the absence of confrontational assertiveness in a manner that hints at female submissiveness.

Eighty per cent of the sculptors in Zimbabwe of the first generation are male (Winter-Irving 1994), whilst Agness 


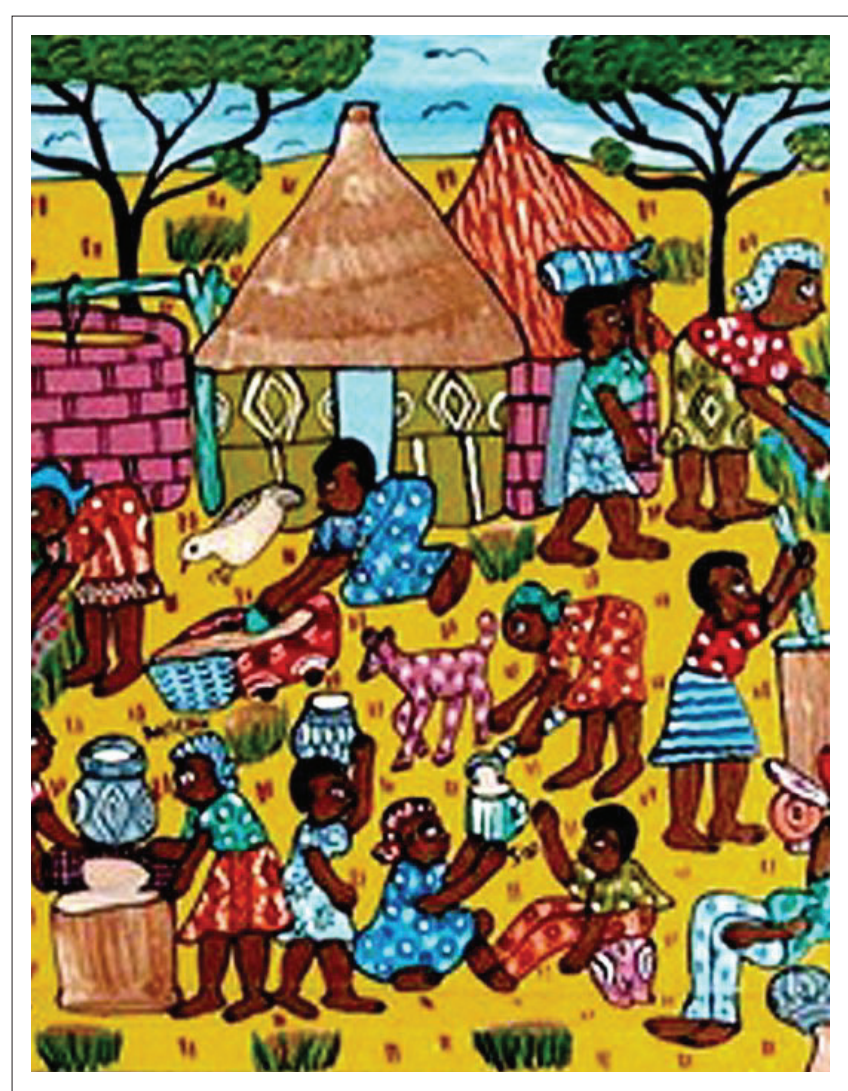

Source: Brookstonbeerbulletin.com, 2009, Beer in Art \#26: Brewing traditional beer in Zimbabwe, viewed n.d., from https://za.pinterest.com/pin/524599056567572872/?d=t\&mt =signupOrPersonalizedLogin

FIGURE 3: Weya women.

Nyanhongo and Letwin Mugavazi are amongst the few women sculptors. They celebrate womanhood with double figures in most of their works such as Sharing strength and Stronger together. One can infer from the titles and sculptures that feminine weakness, dependency and a lack of individual strength or power are quite prevalent.

The Heroes' Acre in Harare is a significant public artwork which was curated and designed by a male artist, David Mutasa, which portrays strong masculine presences (Samwanda 2013). Although some female characters are visible, male domination is clear. In a relief mural placed just below the tomb of the unknown soldiers, women are carved in their domesticated roles carrying babies and food, whilst men are shown carrying guns, doing heavy manual work in the fields and working as ironsmiths. The mural also shows more males than females, which can be seen as another feature that diminishes the role of women in the grand narrative of the liberation struggle. This male-dominated narrative is extended further at the main tomb of the unknown soldiers. The heights of male and female statues also demonstrate their inequality (Goffman 1987) where a male figure towers high above the figure of a female soldier in the three-figure statue.

Female icons in the form of heroic statues and sculptures are practically absent from public art. The public sculptures around Zimbabwe mostly represent and worship masculine dominance, for example, Cecil John Rhodes (Matopos), Farmer

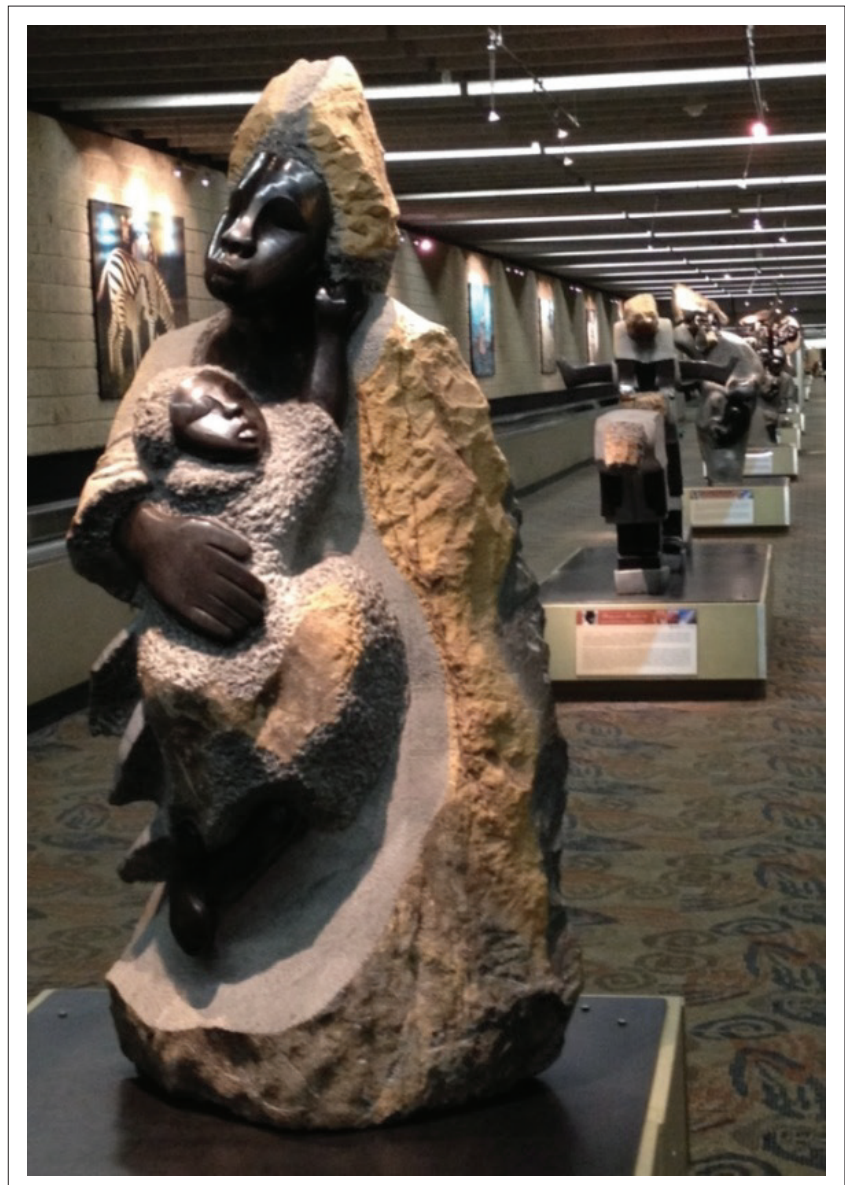

Source: Wikipedia, 2012, Zimbabwe sculpture: A tradition in stone, viewed n.d., from https:// en.wikipedia.org/wiki/Sculpture_of_Zimbabwe

FIGURE 4: First lady stone, Agness Nyanhongo.

(Hurudza House), Joshua M. Nkomo (Main Street, Bulawayo) and Construction workers (Construction house).

Dr Joshua Nyongolo Mqabuko Nkomo died during his tenure as the vice-president of Zimbabwe in 1999 after an illustrious political career. He was one of the main leaders to sign the Lancaster Peace Agreement for the independence of the country whilst leading the Zimbabwe African People's Union (ZAPU) political party. As a national icon, he was nicknamed Father Zimbabwe. A bronze statue of $5 \mathrm{~m}$ (inclusive of the pedestal) in his native city Bulawayo speaks volumes of Nkomo's domineering honour, political power and social status. This statue was re-erected on a pedestal $3 \mathrm{~m}$ high after initial attempts on a lower pedestal had been met with public rejection and was consequently removed a day after its erection (Ndlovu 2017). The lower pedestal was felt to diminish the hegemonic power which was congruent with Dr Nkomo. The statue was then placed in the same location where the north-facing statue of Cecil John Rhodes stood. It is well-known that Rhodes had the ambition to rule Africa from Cape to Cairo. The placement of Dr Nkomo's statue in his stead resembles his political power and intention to rule the whole of Zimbabwe which extends to the north of Bulawayo. The knobkerrie (induku) in his right hand (Figure 5) was used for fighting and also served as a symbol of leadership. 


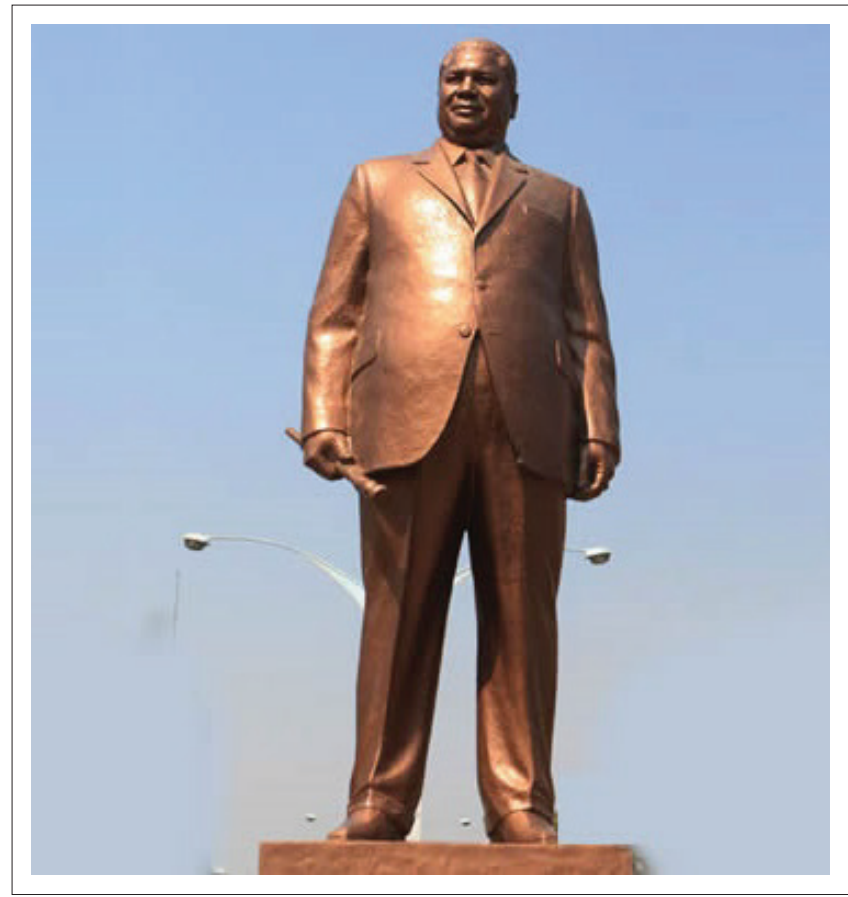

Source: Publicdelivery.org, n.d., The Mansudae overseas project - Zimbabwe - Joshua Nkomo statue, viewed n.d., from https://za.pinterest.com/pin/8022105572664863/

FIGURE 5: Dr Joshua Nyongolo Mqabuko Nkomo, North Korea.

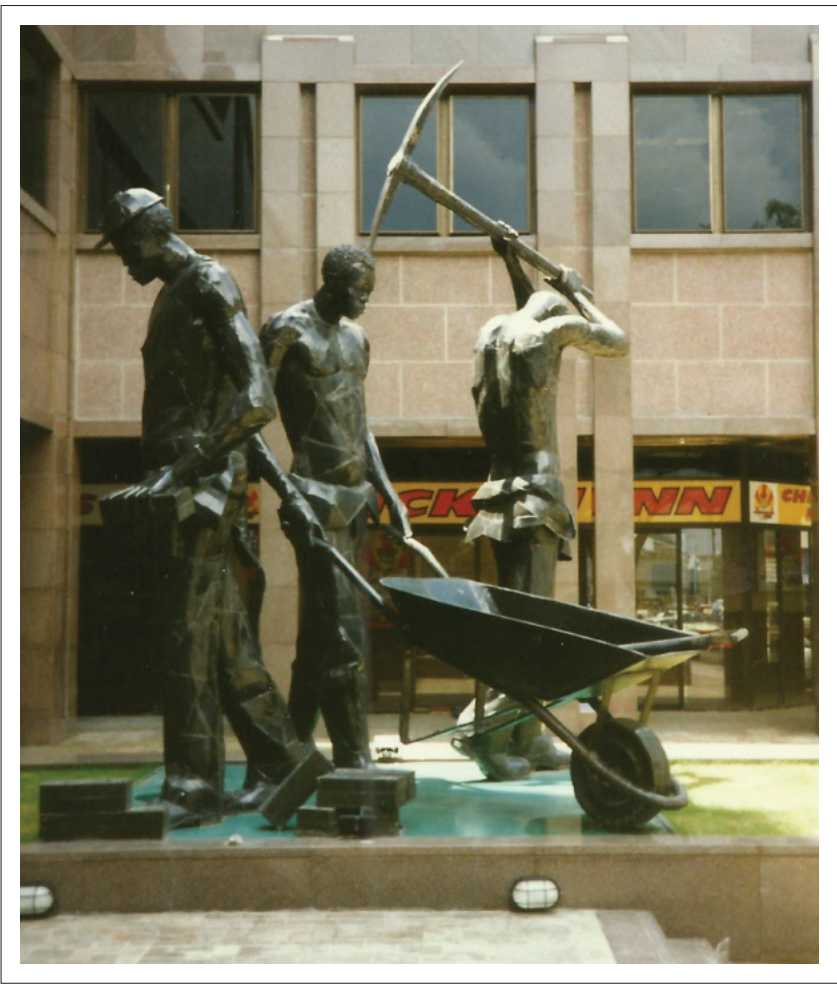

Source: InZart, 1992, Construction workers, viewed n.d., from http://www.inzart.co.uk/ madebe-construction-workers/4586644380

FIGURE 6: Construction workers, Adam Madebe.

A public sculpture installation, Construction workers (1992) by Adam Madebe, predominantly demonstrates gender stereotypes, role segregation and masculine hegemonic views. In 1985, Madebe created a controversial $3.5 \mathrm{~m}$ high sculpture titled Looking into the future depicting a nude man as a visionary leader. In 1992, Madebe was commissioned to create Construction workers (Figure 6). This monumental work, which is $4 \mathrm{~m}$ high, is displayed in an open courtyard in central Harare. Three men are represented doing various construction chores such as bricklaying, pushing a wheelbarrow and digging with a pick, thereby defining and segregating construction work as a male domain. In addition, the size of the statues is intimidating and the muscular male bodies typify the masculine form as suitable for these endeavours.

Art practices in Zimbabwe, therefore, often reflect patriarchal power relations which prevail in the culture. However, these expressions do not go without contestation. The following section testifies to this.

\section{Exiting the mire}

Questioning the male gaze seeks to avert the gendered social prejudices, inequalities and injustices that diminish the visibility and power of women in art practice. Thus, erasure of patriarchal associations, stigmatisation of gender roles, inequity, abuses and other social discriminating practices are contested in some visual spaces. This departure from the stereotypical norm is also associated with a decolonialist thrust that contests hegemonic ideologies and practices, rather applying a critical lense which propound and embrace inclusivity, pluralism, equality and the reversal of gender stereotypes (Quijano 2000).

It may be seen that women have grudgingly tolerated their diminished visibility in social, political, gender and visual spaces. However, these feelings or emotions of resentment, discontentment and displeasure have not always remained suppressed. Women have generated resistant activism through various means, violence, demonstrations, uprising and activist art (Nordlund et al. 2011; Packer 2011).

Art in this sense serves as a vehicle to challenge and provoke patriarchy as well as coloniality (Dewhurst 2014; Olga 2011; Thistlewood 1991). Activist artworks such as The Liberation of Aunt Jemima (1972) by Betye Saar, The Dinner Party (1979) by Judy Chicago, Woman series (1952) by William De Kooning, The Blue Bra Girls (2012) by Amer Ghada, Sophie (2009), Black female body series by Mary Sibande and Love in the Time of Afrophobia (2015) by Sthembile Msezane have emerged over the years to contest male domination and to reverse stereotypical female identities. Mary Sibande, a South African-based artist, uses a mythical domestic servant 'Sophie' to question the notion of inferiority and to challenge injustices and prejudices in the gender, social and political arenas. She transforms her identity from a domestic worker into a Victorian queen or Spiderman (Figure 7) within the post-apartheid era. With Spiderman, Sophie deconstructs a submissive, docile identity to an aggressive heroine breaking the canons of heteronormativity.

The National Gallery of Zimbabwe has hosted several exhibitions such as In praise of Women $(2004,2006)$, Women on Top (2014), Out of Darkness (2015), Discoloured Margins (2017) 
and The equality of women (2018) to promote the visibility of women and to challenge the colonial narratives of females in society. Several Zimbabwean female artists have collectively

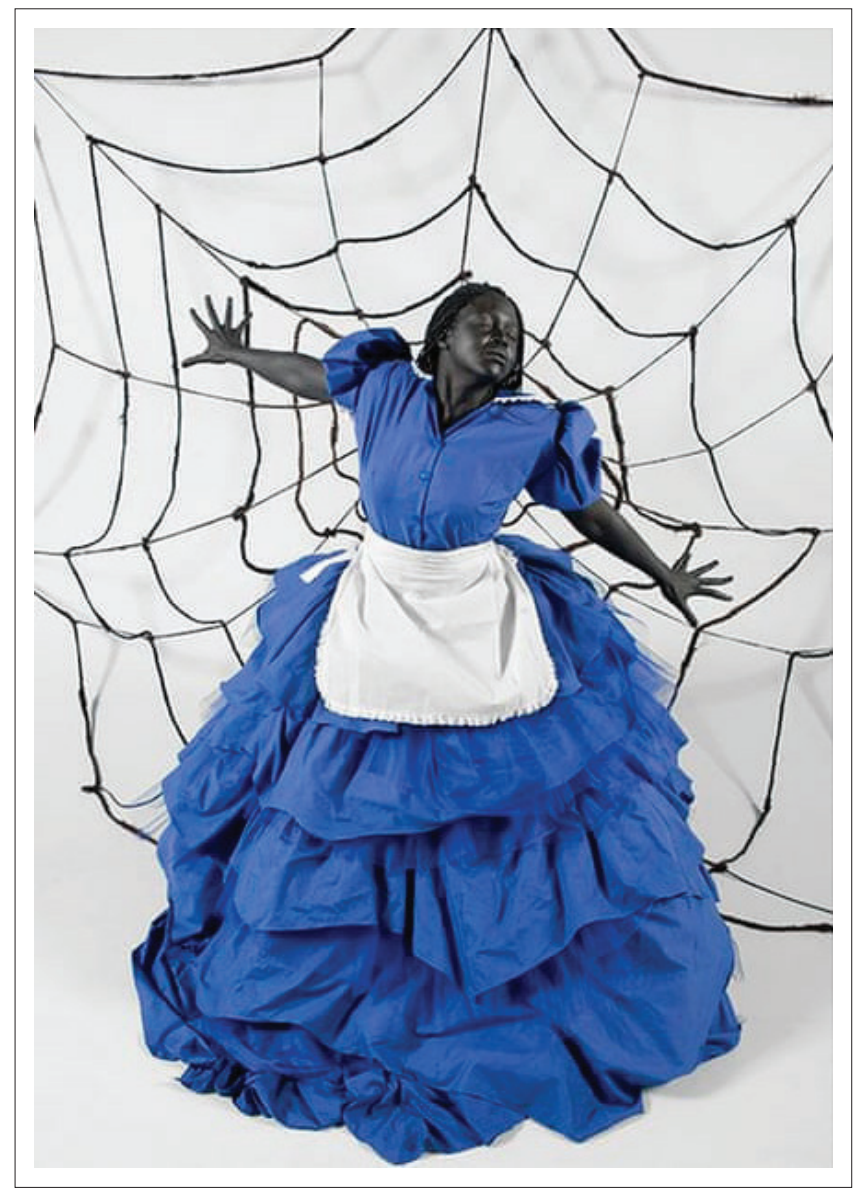

Source: Sibande, M., 2009, Caught in the rapture, viewed n.d., from https://www. theguardian.com/world/2014/jan/07/mary-sibande-south-africa-art

FIGURE 7: Spiderman - Sophie, Mary Sibande. challenged cultural suppression, patriarchy, physical and emotional abuse, lack of empowerment and marginalisation. These artists include Doris Kamupira, Agness Mupariwa, Charmaine Chitate, Agnes Nyanhongo, Colleen Madamombe, Locardia Ndandarika, Letwin Mugavazi, Netsayi Mukomberanwa, Estelle Mbefura, Zanele Anne Mutema and Kressiah Mukwazhi. The colonial narrative of the African women tended to prevent them from producing art for public spaces. Women were relegated to the making of crafts, beadwork, pottery and other ritual and ceremonial objects (Mugambi 2008). The exposure to gallery spaces enables women to raise their voices and enhances their visibility through different mediums, including multi-media, painting, photography and sculpture.

The female art activist photographer Annie Mpalume has used the female image to explore and challenge women's roles and to develop critical consciousness. In the above photographs (Figure 8) exhibited at the National Gallery of Zimbabwe, Mpalume challenges the patriarchal tradition which prioritises marriage for girls over education. Images, such as these, contest patriarchal beliefs that the destiny of a girl is marriage; hence there is no need to invest in her education (Kamabarami 2006). The colonial narrative that prevented women from voicing their grievances, concerns and voting powers is also openly challenged and contested. Inscriptions on t-shirts stand out as voices of their resistance. Mpalume also photographed a woman showing her red-inked finger after casting a vote in Zimbabwe, thereby celebrating her inclusion, democratisation and participation in the voting process.

Zimbabwean artist Doris Kamupira creates feminine visual perspectives in a series of works themed muonevisualarts (translated seehervisualarts) to question the invisibility of women in social, political and religious spheres. Also,

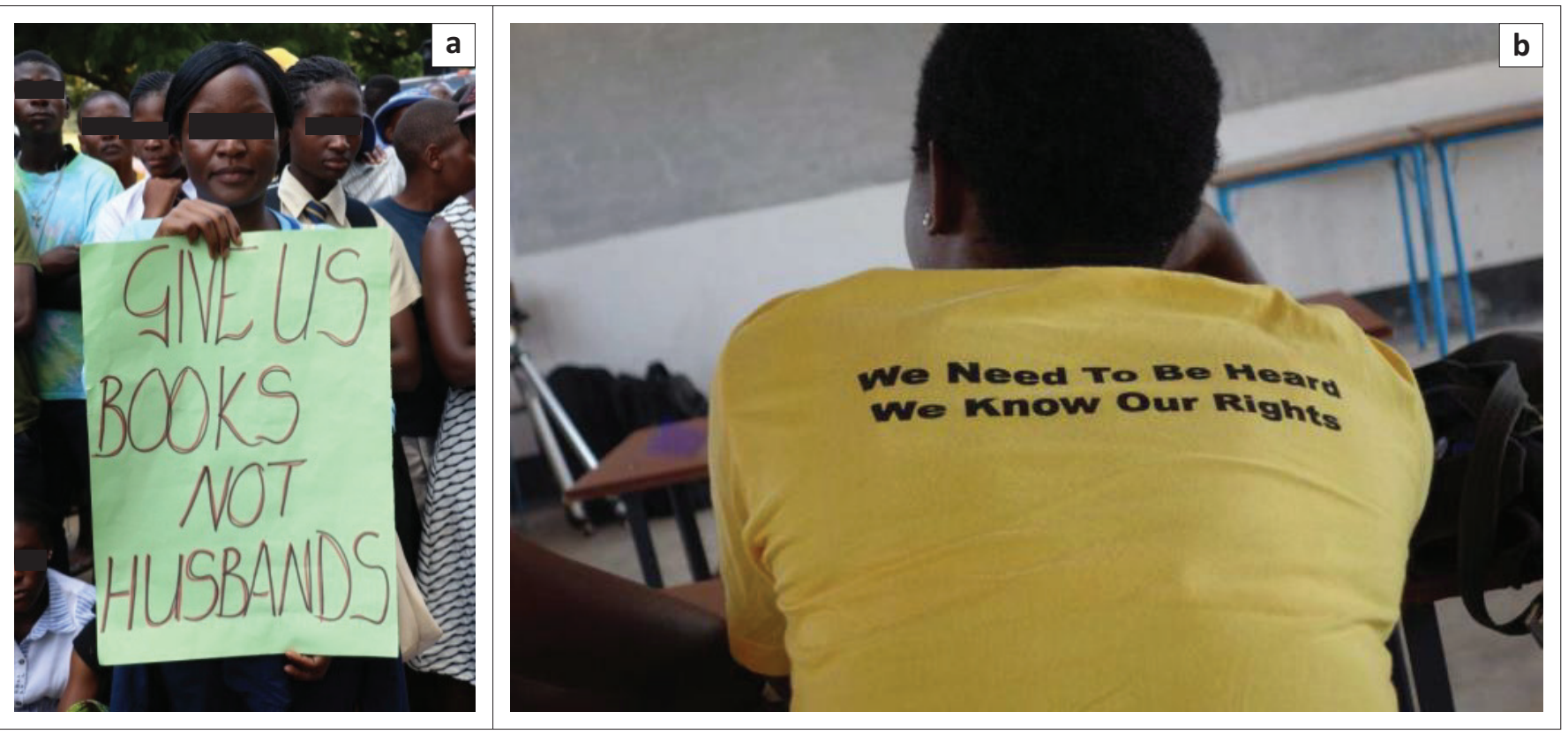

Source: (a) Annie Mpalume, 2017, Give us books not husbands, viewed n.d., from https://nationalgalleryofzimbabwe.blogspot.com/2017/03/give-us-books-not-husbands_6.html; (b) Timesup, 2015, ToR - Exhibition re/calling Siachilaba, viewed n.d., from https://timesup.org/ToR-Exhibition04

FIGURE 8: Photography: (a) child marriages; (b) human rights. 
Tashinga Gondo who exhibited in the Women on Top (2014) exhibition interrogates the stereotyped female position by challenging societal norms and patriarchal narratives which diminished women's visibility in her paintings, mixed-media and installations. Some Zimbabwean art practices, therefore, do challenge patriarchy through the exposure and inclusion of women participating in public art.

\section{Recommendations}

The significance of one's gender and socio-political location and its embodiment in visuality need to be taken seriously. Visual representations that challenge the status quo are salient in the context of the decolonial project that seeks to contest social injustice, inequality, exclusions and oppression based on race, gender, class, sexuality and culture.

The interpretation of artworks suggests that the problem of gender stereotyping may be addressed during the formative years, and therefore working with the youth may help to question and challenge problematic and entrenched views of women. We recommend that engaging in feminist pedagogy at all levels of education can, certainly, contribute to solving unequal relations and discriminatory structures and practices in society and, in doing so, create socially equitable environments. Critical dialogue should continue to find solutions to issues such as pedagogical approaches that could be used to create conditions that enable women artists to transform from passive positions to active critical engagement. Teachers can be used as agents to promote social change through their teaching practices. The classroom provides a conducive environment for sensitisation on gender injustices, awareness and activities about gender equality. Teachers are re-contextualising agents and can function as transformative, intellectual role-models who can exercise influence over content and curriculum transformation and shifts in pedagogic practice and choices about which or whose knowledge(s) are privileged.

In encoding and decoding art, we propose visual analysis models that embrace diversity, inclusion and neutrality which inherently challenge segregation, erasure and oppression. We should seek to imagine and probe forms of collegiality, knowledge sharing and creative engagement fostered within exhibition spaces open for all genders and sexes on national and international levels. This involves continued efforts in deliberately creating and providing more favourable and safe spaces for women artists to express their viewpoints, protests and resistance without fear and intimidation in formal gallery environments. Women's voices, experiences, challenges and needs can be rendered worthy of scholarly engagement, in particular a society that tends to marginalise and exclude them from certain spheres.

\section{Conclusion}

This article engaged with the notions of patriarchy and colonial vestiges present in society and visual production, highlighting these issues together with exploring efforts at decoloniality and gender liberation that women can bring to works of art, films and advertisements. Patriarchal beliefs are fundamental to cultural hegemony and the notion of the male gaze. Zimbabwe's patriarchal society is known to privilege men and subordinate women. This entrenched gender polarisation has a bearing on the production of reception of visual representations that need to be challenged. This article, therefore, explored a number of prejudices associated with Zimbabwe's patriarchal society that can be gaged from visual interpretations by artists, actors and the viewers privileging the male gender in Zimbabwe. However, the decolonial project is subverting these art practices by providing spaces for women to challenge colonial vestiges as well as patriarchy. The oppressive, diminishing, abusive and marginalising narrative can be altered, subverted and reconstructed with the aim of achieving equality.

\section{Acknowledgements Competing interests}

The authors have declared that no competing interest exists.

\section{Authors' contributions}

All authors contributed equally to this work.

\section{Ethical consideration}

This article followed all ethical standards for carrying out research.

\section{Funding information}

The research received no specific grant from any research agency in the public, commercial or not-for-profit sectors.

\section{Data availability statement}

Data sharing is not applicable to this article as no new data were created or analysed in this study.

\section{Disclaimer}

The views and opinions expressed in this article are those of the authors and do not necessarily reflect the official policy or position of any affiliated agency of the authors.

\section{References}

Annie Mpalume, 2017, Give us books not husbands, viewed n.d., from https:// nationalgalleryofzimbabwe.blogspot.com/2017/03/give-us-books-not-husbands_6. html

Artsandculture.google.com, n.d., Masimba Hwati. Urban Totems 6.., viewed n.d., from https://artsandculture.google.com/asset/masimba-hwati-urban-totems-6/ FQGzm2Fr-kaqiw

Artsandculture.google.com, n.d., Masimba Hwati. Urban Totems 2.., viewed n.d., from https://artsandculture.google.com/asset/masimba-hwati-urban-totems-2/ LgGOfpgYOV16gw

Barnet, S.A., 2010, Short guide to writing about art, Longman, New York, NY.

Brookstonbeerbulletin.com, 2009, Beer in Art \#26: Brewing traditional beer in Zimbabwe, viewed n.d., from https://za.pinterest.com/pin/52459905656757287

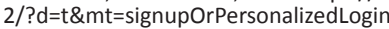

Bourdieu, P., 2001, Masculine domination, Stanford University Press, Redwood City, CA. 
Butler, J., 1991, Gender trouble: Feminism and the subversion of identity, Routledge, New York, NY.

Chabaya, O. \& Gudhlanga, E.S., 2007, 'Striving to achieve gender equity in education: A Zimbabwean experience, successes and challenges', Zimbabwe Journal of Educational Research 25(1), 1-14.

Chabaya, O., Rembe, S. \& Wadesango, N., 2009, 'The persistence of gender inequality in Zimbabwe: Factors that impede the advancement of women into leadership positions in primary schools', South African Journal of Education 29(2), 235-251. https://doi.org/10.15700/saje.v29n2a259

Connell, R. \& Messerschmidt, J.W., 2005, 'Hegemonic masculinity: Rethinking the concept', Gender \& Society 19(6), 829-859. https://doi.org/10.1177/0891243 205278639

Creswell, J.W., 2013, Qualitative inquiry and research design: Choosing among five approaches, 3rd edn., Sage, London.

De Vos, A.S., Strydom, H., Fouché, C.B. \& Delport, S.L.C., 2011, Research at grassroots for the social sciences and human service professions, 4th edn., Van Schaik, Pretoria.

Derrida, J., 1982, 'Deconstruction in context: Literature and philosophy', in M.C. Taylor (ed.), Difference, pp. 19-30, University of Chicago Press, Chicago, IL.

Dewhurst, M., 2014, Social justice art: A framework for activist pedagogy, Harvard Educational Books, Cambridge.

Diamond, M., 2002, 'Sex and gender are different: Sexual identity and gender identity are different', Clinical Child Psychology \& Psychiatry 7(3), 320-334. https://doi. org/10.1177/1359104502007003002

Dudu, W., Gonye, J., Mareva, R. \& Sibanda, J., 2008, 'The gender sensitivity of the Zimbabwean secondary school textbooks', Southern Africa Review of Education 14(3), 73-88.

Dziwa, D.D., 2016, The role of gender polarisation in visual interpretation by Zimbabwean undergraduate art teacher education students, North-West University, Potchefstroom.

Freud, S., 1955, From the history of an infantile neurosis: Complete psychological works, Hogarth, London.

InZart, 1992, Construction Workers, viewed n.d., from http://www.inzart.co.uk/ madebe-construction-workers/4586644380

Goffman, E., 1987, Gender advertisements, Harper \& Row, New York, NY.

Gordon, R., 1994, 'Educational policy and gender in Zimbabwe', Gender and Education 6(2), 131-139. https://doi.org/10.1080/0954025940060203

Gramsci, A., 1994, Selection from the Prison notebooks, Lawrence \&Wishart, London.

Gudhlanga, E.S., Chirimuuta, C. \& Bhukuvhani, C., 2012, 'Towards a gender inclusive curriculum in Zimbabwean Education system: Opportunities and challenges', Gender and Behaviour 10(1), 4533-4545.

Kaboy, V., 2015, 'Zimbabwean visual art shining in Venice', Harare News, viewed 18 October 2019, from http://www.hararenews.co.zw/2015/06/zimbabwean-visualart-shining-in-venice/

Kamabarami, M., 2006, Femininity, sexuality and culture: Patriarchy and female subordination in Zimbabwe, University of Forth Hare, Forth Hare.

Kress, G., 2010, Multimodality: A social semiotic approach to contemporary communication, Routledge, London.
Kristeva, J., 1980, Desire in language: A semiotic approach to literature and art, Columbia University, New York, NY.

Messerschmidt, J.W., 2019, 'The Salience of "Hegemonic Masculinity"', Men and Masculinities 22(1), 85-91. https://doi.org/10.1177/1097184X18805555

Mugambi, H.N., 2008, 'Zimbabwean feminist art and the politics of representation', Zimbabwe Journal of Educational Research 32(2), 424-430. https://doi.org/ $10.1086 / 521060$

Mulvey, L., 1999, 'Visual pleasure and narrative cinema', in L. Braudy \& M. Cohen (eds.), Film, theory and criticism: Introductory readings, pp. 833-844, Oxford University Press, Oxford.

Mutekwe, E. \& Mobida, M., 2014, 'Perceived gender-based challenges endured by Zimbabwean secondary school girls in their academic and occupational prospects', Perspectives in Education 31(1), 20-30.

Ndlovu, T., 2017, 'Whose Nkomo is it anyway? Joshua Nkomo's statue and commemorative landscape', in S.J. Ndlovu-Gatsheni (ed.), Joshua Mqabuko Nkomo of Zimbabwe: Politics, power, and memory, pp. 405-439, Palgrave Macmillan, Cham.

Nordlund, C., Speirs, P., Stewart, M. \& Chicago, J., 2011, 'Activist art and pedagogy: The dinner party curriculum project', in B. Beyerbach \& R.D. Davis (eds.), Activist art in social justice pedagogy: Engaging students in global issues through the arts, pp. 134-153, Peter Lang, New York, NY.

Olga, H., 2011, 'Rethinking critical thinking and its role in Art Museum education', The Journal of Aesthetic Education 45(3), 15-21.

Packer, M., 2011, The science of qualitative research, Cambridge University Press, Cambridge.

Parpart, J.L., 1995, Gender, patriarchy and development in Africa: The Zimbabwean case, Women and International Development Program, Michigan State Universiry, East Lansing, MI.

Publicdelivery.org, n.d., The Mansudae Overseas Project - Zimbabwe - Joshua Nkomo Statue, viewed n.d., from https://za.pinterest.com/pin/8022105572664863/

Quijano, A., 2000, 'Coloniality of power and eurocentrism in Latin America', International Sociology 15(2), 215-232. https://doi.org/10.1177/0268580900015002005

Samwanda, B., 2013, Post-colonial monuments and public sculpture in Zimbabwe, Rhodes University, Grahamstown.

Sibande, M., 2009, Caught in the rapture, viewed n.d., from https://www.theguardian. $\mathrm{com} /$ world/2014/jan/07/mary-sibande-south-africa-art

Thistlewood, D., 1991, Critical studies in art and design education, Heineman Educational Books, Portsmouth.

Timesup, 2015, ToR - Exhibition re/calling Siachilaba, viewed n.d., from https:// timesup.org/ToR-Exhibition04

Tiwani.co.uk, 2019, Gareth Nyandoro, Pajoji Electricals, viewed n.d., from https:// za.pinterest.com/pin/480970435207889175/

Winter-Irving, C., 1994, Contemporary stone sculpture in Zimbabwe: Context, content and form, Craftsman House, Harare.

Wikipedia, 2012, Zimbabwe sculpture: A tradition in stone, viewed n.d., from https:// en.wikipedia.org/wiki/Sculpture_of_Zimbabwe

Zimstat, 2016, Facts and figures, Zimstat Main Publications, Harare, viewed 19 June 2019, from http://www.zimstat.co.zw/sites/default/files/img/publications/ Facts $\% 20$ and $\% 20$ Figures/Fact_Figures2016.pdf. 